\title{
Ocular Melanoma with Extraocular
} Extension

National Cancer Institute

\section{Source}

National Cancer Institute. Ocular Melanoma with Extraocular Extension. NCI Thesaurus.

Code C7913.

A melanoma arising from and extending beyond the structures of the eye. 